\title{
0 Monocultivo da Araucaria angustifolia na Floresta Nacional de Passo Fundo, Brasil (1947-1960)
}

The Monoculture of Araucaria angustifolia in the National Forest of Passo Fundo, Brazil (1947-1960)

\author{
Marcos Gerhardt y Débora Nunes de Sá* \\ [marcos@gerhardt.pro.br / nunesdesaa@gmail.com]
}

Recibido: 6 de diciembre de 2016

Aprobado: 12 de marzo de 2017

DOl:

Cita sujerida: Gerhardt, Marcos; Sá, Débora Nunes. "0 monocultivo da Araucaria angustifolia na

Floresta Nacional de Passo Fundo, Brasil (1947-1960)." HALAC VII, no.1 (junio): 42-57.

\begin{abstract}
RESUMO
A região de ocorrência endêmica da Floresta Ombrófila Mista no sul do Brasil foi, no início do século XX, transformada pela indústria madeireira, o que ocasionou a redução da área florestal contendo espécies nativas madeiráveis. Em contrapartida, o Instituto Nacional do Pinho aplicou o "Plano de Reflorestamento" como tentativa de repor a matéria-prima florestal que se tornou escassa. Este artigo dedica-se a narrar e analisar as atividades desenvolvidas no então Parque Florestal José Segadas Viana - atualmente a Floresta Nacional de Passo Fundo durante os anos de 1947 a 1960, período no qual o Parque teve por função desenvolver técnicas experimentais de plantio e manejo da espécie arbórea nativa Araucaria angustifolia. A partir da interpretação de diversas fontes de pesquisa, grande parte inédita, concluiu que o conhecimento produzido no Parque serviu aos propósitos do Instituto Nacional do Pinho e que as práticas de monocultivo construíram um agroecossistema florestal.
\end{abstract}

\section{Palavras chave}

Instituto Nacional do Pinho, Parque Florestal, Monocultivo, Araucaria angustifolia, Agroecossistema.

\section{ABSTRACT}

The region of endemic occurrence of the Mixed Ombrophilous Forest in southern Brazil, was transformed in the early $X X$ century by the timber industry, which led to the reduction of the forest area containing wood species. On the other hand, the National Pine Institute applied the "Plan of Reforestation" as an attempt to replace the forest raw material that became scarce. This article is dedicated to narrating and analyzing the activities developed in the then José Segadas Viana Forest Park - currently the National Forest of Passo Fundo - during the years 1947 to 1960, during which time the Park had to develop experimental techniques of planting and management of native tree species Araucaria angustifolia. From the interpretation of several sources of research, it was concluded that the knowledge produced served the purposes of the National Pine Institute and that monoculture practices built a forest agroecosystem.

\section{KEYWORDS}

National Pine Institute, Forest Park, Monoculture, Araucaria angustifolia, Agroecosystem.

\footnotetext{
* Doutor em História pela Universidade Federal de Santa Catarina (UFSC). Professor no Curso de Graduação em História e no Programa de Pós-Graduação em História da Universidade de Passo Fundo (UPF). / Mestre em História pela Universidade de Passo Fundo. Bolsista CAPES.
} 


\section{Introdução}

A Floresta Nacional de Passo Fundo (FLONA PF) é, atualmente, uma unidade de conservação de uso sustentável, localizada no município de Mato Castelhano, estado do Rio Grande do Sul. Possui superfície de 1.275 hectares e encontra-se inserida na grande área de ocorrência endêmica da Floresta Ombrófila Mista (FOM) ou Floresta com Araucária. A área foi adquirida em 1946 pelo Instituto Nacional do Pinho (INP), órgão paraestatal criado em 1941. As terras compradas pelo INP possuíam, naquele período, aproximadamente 350 hectares remanescentes de FOM, 0 restante era área agricultável, de pastoreio e de residência. ${ }^{1}$

Nesse lugar criou-se o Parque Florestal José Segadas Viana, em homenagem à Segadas Viana, ligado ao Partido Trabalhista Brasileiro que, em 1945, assumiu como deputado na Assembleia Nacional Constituinte com mandato renovado em $1950 .{ }^{2}$ Seu nome tinha significado nacional, mas não havia ligação com o local onde o Parque foi estabelecido. Em 1967, o INP foi extinto e o Instituto Brasileiro de Desenvolvimento Florestal (IBDF) assumiu suas funções. Em 1968, o Parque Florestal José Segadas Viana passou a denominar-se Floresta Nacional de Passo Fundo.

Nesse artigo, interpreta-se variada documentação gerada no Parque Florestal e na FLONA PF, que permite narrar e explicar a produção de um conhecimento sobre o plantio e 0 manejo da Araucaria angustifolia, seu monocultivo para uso pela indústria madeireira e a criação de um agroecossistema florestal, entre 1947-1960. A interpretação se fundamenta nas referências conceituais elmetodológicas da História Ambiental.

\section{Os parques florestais}

A Resolução n. 13 de 1944, publicada no Diário Oficial da União, determinou que a Divisão de Economia Florestal do INP devia "Receber ou adquirir de órgãos públicos ou de particulares áreas de terras para reflorestamento", para a criação de "florestas artificiais" a serem exploradas pelo Instituto Nacional do Pinho com o propósito de manter o suprimento de madeira para o comércio e a indústria. Determinou também que o INP era responsável por aplicar o chamado "Plano de Florestamento." 3 Esse Plano previa a criação de parques florestais em "[...] glebas de terras com áreas onde se possam desenvolver programas de reflorestamento durante período mínimo de cinco anos", os quais deveriam ser instalados em São Paulo, Santa Catarina, Paraná e Rio Grande do sul, em "zonas adequadas e servidas por rodovias ou ferrovias de acesso."

0 INP instituiu, ao todo, dez parques florestais: um no estado de Minas Gerais, um em São Paulo, dois no Paraná, três em Santa Catarina e três no Rio Grande do Sul (localizados nos municípios de São Francisco de Paula, Canela e no então município de Passo Fundo). Eles tinham como finalidade estudar 0 cultivo e 0 crescimento da Araucaria angustifolia em diferentes condições bióticas e abióticas. 0 Código Florestal de 19345, vigente na década de 1940, quando a maioria dos parques florestais foi criada, os incluiu na categoria de "florestas modelo", com a finalidade de produzir espécies arbóreas nativas e exóticas para disseminação entre particulares, 0 que por sua vez constituiria matéria-prima florestal, possibilitando a ampliação de mercados para a madeira. Assim, sua função preponderante era atender a uma demanda de mercado, ou seja, aos interesses econômicos da nação.

\footnotetext{
1 CRIPF. Cartório de Registro de Imóveis de Passo Fundo. Cópia da Certidão n. 23.875/2008. Livro de Registro de Transmissão do Cartório de Registro de Imóveis de Passo Fundo. Arquivo da Floresta Nacional de Passo Fundo.

${ }^{2}$ CPDOC. Centro de Pesquisa e Documentação de História Contemporânea do Brasil. Biografia de José Segadas Viana. (Rio de Janeiro: FGV, 2001). http://cpdoc.fgv.br/producao/dossies/AEraVargas2/biografias/Segadas_Viana.

${ }^{3}$ Brasil. Resolução n. 13 de 1 de abril de 1944. Instituto Nacional do Pinho. (Rio de Janeiro, 4 de abril de 1944). https://www.jusbrasil.com.br/diarios/2265906/pg-29-seca0-1-diario-oficial-da-uniao-dou-de-04-04-1944.

${ }^{4}$ Ibidem.

${ }^{5}$ Brasil. Decreto n. 23.793 de janeiro de 1934. Aprova o Código Florestal. (Rio de Janeiro, 23 de janeiro de 1934) http://www.planalto.gov.br/ccivil_03/decreto/1930-1949/d23793.htm.
} 
0 INP precisou estudar as características ecológicas da araucária e 0 seu desenvolvimento, adequando 0 método de plantio às características de cada local e assegurando algum retorno financeiro ao investimento realizado. A produção de material lenhoso proveniente das plantações destinou-se ao mercado regional (indústria madeireira ou de celulose), e os conhecimentos produzidos foram compartilhados com particulares (em sua maioria agricultores) interessados no plantio de araucária. Dessa forma, o Instituto Nacional do Pinho foi o principal agente na construção do agroecossistema dos parques florestais administrados pela autarquia.

0 "Plano de Reflorestamento" aplicado pelo Instituto Nacional do Pinho demandou uma série de investimentos, que iam desde a aquisição de terras até a compra de materiais básicos para a manutenção dos parques florestais, a abertura de estradas e a construção de prédios. Nos primeiros cinco de anos de atividades dos parques (1944-1950), o órgão contabilizou a aplicação de aproximadamente 27 milhões de cruzeiros. ${ }^{6}$ Em Passo Fundo o processo de aquisição, foi marcado por um conflito que envolveu os ex-proprietários de terras, os mediadores da negociação, o Instituto Nacional do Pinho e a imprensa regional. ${ }^{7}$

Eudoro Barros, Chefe da Divisão de Florestamento e Reflorestamento do INP e responsável pelo "Plano de Reflorestamento", avaliou que os plantios realizados nos parques florestais da autarquia podiam ser classificados em duas fases distintas: a primeira durante 0 período de 1944 a 1951 e a segunda, nos anos seguintes até fins da década de 1960. Escreveu ele que, na primeira fase, o Instituto Nacional do Pinho lançou-se na "faina de reflorestar com pinheiros, sem outra orientação que a de observações feitas nas raras plantações então existentes" e teve que investir seus recursos na compra de terras "para dar expansão ao reflorestamento, em vista de não ter encontrado éco ao apêlo feito aos Estados e Municípios no sentido de lhe serem doadas terras para o fim a que se propunha." ${ }^{8}$ Além disso, Barros apontou que a conjuntura daquele período, marcada pela Segunda Guerra Mundial (1939-1945), impossibilitou a aquisição de implementos agrícolas e tratores, o que por consequência prejudicou a preparação de terras para os plantios, feitas então com arado de tração animal e, em alguns casos, sem receber preparação alguma. Isso também prejudicou os tratos culturais, que foram realizados manualmente com o uso de enxada. A segunda fase se deu a partir de 1952, período em que a maioria dos parques possuía sua infraestrutura instalada, o que permitiu a aquisição de tratores e implementos, reduzindo 0 trabalho humano e 0 custo dos plantios e dos tratos culturais. ${ }^{9}$

\section{O Parque Florestal José Segadas Viana}

Em Passo Fundo, município do norte do estado do Rio Grande do Sul, para a prática do monocultivo de araucária no Parque Florestal José Segadas Viana, os 1.275 hectares de terras foram distribuídos em talhões. Essa divisão possuía a finalidade de delimitar áreas com características homogêneas, que apresentassem certa igualdade quanto à espécie plantada, densidade e idade do povoamento florestal, ou seja, com capacidade produtiva semelhante. Essa divisão também proporcionava acesso aos povoamentos para a realização dos tratos culturais e permitia um controle estatístico das produções.

Donald Worster defendeu que, embora o agroecossistema seja uma produção humana, ele continua a ser dependente do mundo natural, "da fotossíntese, dos ciclos bioquímicos, da estabilidade

\footnotetext{
${ }^{6}$ Virgílio Gualberto, "A política econômica da indústria da madeira", in Anuário Brasileiro de Economia Florestal 2, (1949): 916.

${ }^{7}$ Cf. Débora Nunes de Sá, Marcos Gerhardt, "Uma história ambiental da Floresta Nacional de Passo Fundo: a aquisição das terras", in Revista Internacional Interdisciplinar INTERthesis 3, (2016): 182-202, https://periodicos.ufsc.br/index.php/interthesis/article/view/1807-1384.2016v13n3p182.

${ }^{8}$ Eudoro Haeckel Lins de Barros, "As atividades do Instituto Nacional do Pinho", in Anais da Reunião Florestal de Itatiaia 12 , (1957): 82.

${ }_{9}$ Ibidem, p. 83.
} 
da atmosfera, e dos serviços de organismos não-humanos", ${ }^{10}$ ou seja, uma complexa combinação de elementos naturais e culturais. Em Passo Fundo, o ecossistema passou a ser reorganizado e foi convertido por meio da ação humana em um agroecossistema para atender necessidades externas e econômicas.

No arquivo da Floresta Nacional de Passo Fundo encontram-se diversos Registros de Talhões, nos quais foram registrados dados que possibilitam identificar como se deu a construção do agroecossistema. Eles apresentam a área total do talhão e a área de efetivo plantio, o espaçamento utilizado entre a cova de uma árvore e outra, o número total de covas, a procedência das sementes, a natureza de cobertura do solo, a contagem das árvores que sobreviveram, 0 número de árvores replantadas e o número de replantios necessários. Esta fonte contém, também, apontamentos sobre os procedimentos realizados na preparação da terra, semeadura e tratos culturais que envolviam diversas etapas sucessivas, bem como os custos parciais e totais dessas atividades. Contudo, nem todos os registros apresentam as informações completas, não são uniformes, e, ao longo do tempo, alguns talhões foram reconfigurados, atribuindo-lhes outra numeração. Afora isso, alguns talhões plantados com araucária não obtiveram êxito e, nas décadas de 1960 e 1970, foram substituídos por povoamentos de Pinus spp e Eucalyptus spp.

Mesmo com falhas e lacunas, os Registros de Talhões foram utilizados como fontes de pesquisa e permitiram identificar as características do monocultivo de árvores praticado na Floresta Nacional de Passo Fundo. José d'Assunção Barros observou que o uso dessa tipologia de fonte possibilita "a serialização de dados, a identificação de elementos ou ocorrências comuns que permitam a identificação de um padrão e, na contrapartida, uma atenção às diferenças, às vezes graduais, para se medirem as variações." ${ }^{11}$ Por outro lado, os Registros de Talhões, enquanto fontes seriais, também são quantitativos, pois trazem informações relativas à quantidade, mortalidade e sobrevivência das espécies arbóreas cultivadas na FLONA PF. 0 objetivo, portanto, do uso das fontes seriais e quantitativas é "[...] abordar fontes com algum nível de homogeneidade que se abram para a possibilidade de quantificar ou de serializar as informações ali perceptíveis no intuito de identificar regularidades"12 e, acresça-se, as diferenças.

Barros alertou os historiadores a não realizarem uma história que contemple somente informações numéricas: "Se a sua História Quantitativa se resumir a uma exposição de quantidades, será meramente uma história descritiva, não-problematizada." ${ }^{13}$ Nesse sentido, busca-se, não somente descrever quantidades e procedimentos utilizados nos monocultivos realizados na FLONA PF, mas compreendê-los dentro da complexa dinâmica do agroecossistema da Floresta Nacional de Passo Fundo. Isto posto, seguem reunidos na Tabela 1 os dados referentes aos talhões plantados com araucária em 1947.

Tabela 1 - Plantio de Araucaria angustifolia no Parque Florestal José Segadas Viana em 1947

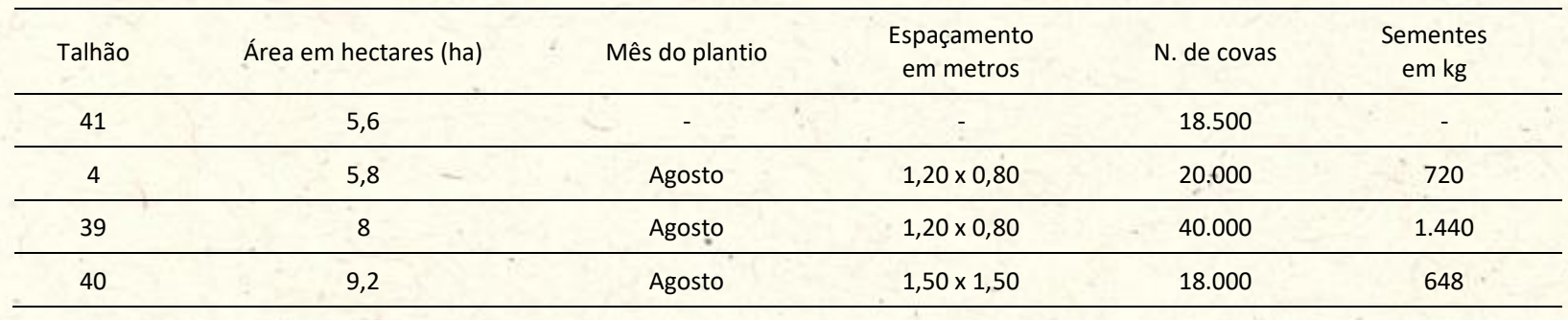

\footnotetext{
${ }^{10}$ Donald Worster, "Transformações da terra: para uma perspectiva agroecológica na história", in Ambiente \& Sociedade 2 , (2003): 29-30.

${ }^{11}$ José D’Assunção Barros, "História Serial, História Quantitativa e História Demográfica: uma breve reflexão crítica", in Revista de Ciências Humanas 1, (2011): 165, http://www.cch.ufv.br/revista/pdfs/artigo5evol11-1.pdf.

12 Ibidem, p. 166.

${ }^{13}$ Ibidem, p. 166.
} 


\begin{tabular}{cccccc}
\hline 46 & 2,8 & Agosto & $1,50 \times 1,50$ & 20.000 & - \\
\hline 47 & 7,6 & Agosto & $1,50 \times 1,50$ & 36.000 & - \\
\hline 48 & 7,6 & Setembro & $1,50 \times 1,50$ & 36.000 & - \\
\hline 42 & 2,4 & Outubro & $1,20 \times 0,80$ & 15.500 & 666 \\
\hline 49 & 3,6 & Outubro & $1,20 \times 0,80$ & 10.000 & 468 \\
\hline Total: & 52,6 & & & 214.000 & 3.942 \\
\hline
\end{tabular}

Fonte: Elaborada pelos autores a partir de Instituto Nacional do Pinho. Parque Florestal José Segadas Viana, Mato Castelhano - Passo Fundo. Registros de Talhões n. 4, 39, 40, 41, 42, 46, 47, 48, 49. Arquivo da Floresta Nacional de Passo Fundo.

Nota: Um quilograma de sementes de pinhões possui aproximadamente 120 unidades.

No total foram plantados com Araucaria angustifolia nove talhões que, juntos, somavam 52,6 hectares de terras. De acordo com o Registro de Talhões, a implantação dos povoamentos florestais previu um processo com diversas etapas sucessivas. Começava pela roçada, registrada como "desbravamento". da terra, que tinha a finalidade de cortar a vegetação de capoeira presente no talhão, geralmente à foice, abrindo, dessa forma, lugar para introduzir a monocultura. Parte da roçada foi realizada pelo "pessoal variável", trabalhadores eventuais também chamados de tarefeiros. Trabalhavam por empreitada e recebiam conforme 0 acordado, que podia ser estabelecido por dia, por hora, por alqueire ou metro quadrado trabalhado. ${ }^{14}$

Depois da roçada, aceiros largos (faixas sem vegetação para evitar que o fogo se propague) eram abertos e a vegetação seca existente no talhão recebia a primeira queimada. A seguir, se procedia ao "encoivaramento", que consistia em uma segunda queimada para eliminar a vegetação que havia restado na primeira. Após 0 encoivaramento, fazia-se 0 destocamento, retirando todos os tocos de árvores restantes no terreno. Encerrava-se, desse modo, a etapa do "desbravamento", isto é, a limpeza da terra. ${ }^{15}$

Iniciava-se, a seguir, a "preparação do terreno", que consistia no "ajunte do raizame", seguido da "lavração" da terra com o uso do arado e novamente o "ajunte do raizame", prosseguindo-se com a "gradagem". Para tal, utilizava-se o implemento agrícola chamado de grade, que tem a finalidade de desfazer torrões e dar homogeneidade a superfície do terreno. Essas atividades estão nos Registros de Talhões, mas não foram preenchidos os custos e nem as datas de realização desses procedimentos nos plantios de 1947, exceto pelo talhão 40, no qual o "ajunte de raizame" foi feito em agosto. Portanto, é difícil assegurar que essa etapa foi realizada em todos os talhões. ${ }^{16}$

A terceira etapa, chamada "sementes", era a separação dos pinhões "bons" dos "ruins". A primeira seleção era feita à mão, eliminado as sementes menores que se localizam na parte superior $\mathrm{e}$ inferior da pinha, as que estivessem atacadas pela broca (praga que pode afetar as sementes, a Cydia araucariae) e as que apresentassem a casca com manchas, o que significa que estão em processo de decomposição.

Depois da seleção da semente, a etapa seguinte era o "plantio", no qual se realizava as atividades de "alinhamento e coveamento". No Relatório Anual de 1946, do Parque Florestal dos Pardos, hoje a Floresta Nacional de Três Barras SC, 0 alinhamento, o coveamento e o plantio definitivo foram bastante detalhados. Os operários estavam divididos em três turmas: a turma de verificação, a de coveamento e a turma de plantio propriamente dito. Conforme o relato do procedimento:

\footnotetext{
${ }^{14}$ Instituto Nacional do Pinho. Livro Caixa n. 1, de 1947-1949 in Parque Florestal do Instituto Nacional do Pinho. Arquivo da Floresta Nacional de Passo Fundo.

${ }^{15}$ Instituto Nacional do Pinho. Parque Florestal "José Segadas Viana", Mato Castelhano - Passo Fundo. Registros de Talhões n. 4; 39; 40; 41; 42; 46; 47; 48; 49. 1947. Arquivo da Floresta Nacional de Passo Fundo.

${ }^{16}$ Instituto Nacional do Pinho. Parque Florestal "José Segadas Viana", Mato Castelhano - Passo Fundo. Registros de Talhões n. 4; 39; 40; 41; 42; 46; 47; 48; 49. 1947. Arquivo da Floresta Nacional de Passo Fundo.
} 
Esta operação foi executada obedecendo tecnicamente as normas recomendadas para o plantio da espécie florestal em apreço, covas não profundas com $5 \mathrm{cms}$. em média, o que facilita 0 desenvolvimento inicial da planta.

$[\ldots]$

Para o plantio no espaçamento de 1,5 mts. usamos cordas finas de 120 metros de extensão, subdivididas no referido espaçamento, por marcas de pano em cores bem vivas, marcas estas moveis podendo-se assim deslocá-las de acordo com a necessidade.

No espaçamento de $1 \mathrm{mt}$. e $2 \mathrm{mts}$. usamos cordas de 100 metros de extensão, dotadas do mesmo sistema de marcas.

Uma vez estendidas no terreno, eram as referidas cordas reconferidas à trena, sendo este 0 serviço da turma 1.

A turma 2 executava a coveação, sendo 0 enxadão, 0 instrumento usado para este serviço.

Em cada corda transversal, colocávamos três homens, sendo dois para segurar a corda pelas extremidades e 1 para abrir as covas.

Esses homens se revezavam no serviço, tornando-se mais leve e expedito 0 ato de covear.

No serviço de plantio propriamente dito, serviço da turma 3 , um operário distribuía alternadamente sementes por entre duas linhas de covas.

$[\ldots]$

Ainda em canteiros, plantamos não somente para experimentação, como também para obter mudas necessárias na previsão de falhas no plantio [sic] (grifo do autor). ${ }^{17}$

Por serem parques administrados pela mesma autarquia e com o mesmo objetivo, possivelmente esse procedimento ocorreu de forma semelhante no Parque Florestal José Segadas Viana em 1947. 0 Relatório do Parque Florestal dos Pardos ainda informou que o "ato de colocar a semente na cova foi executado por menores, quasi sempre filhos de operários deste Parque, resultando dai baratia do custo deste serviço" [sic]..$^{18}$ Ermes Miorando, funcionário aposentado da Floresta Nacional de Passo Fundo, relatou: "a gente se criou trabalhando na FLONA. Com 12 anos eu já trabalhava para ganhar um troquinho, mas efetivo foi em junho de 1967, recebendo com carteira assinada até 1996, quando eu me aposentei". ${ }^{19}$ Alfredo da Rosa, também funcionário aposentado, relatou que nasceu em 1947 e que "até uns 10, 12 anos trabalhava por hora", sendo efetivado quando completou 18 anos de idade. ${ }^{20}$ Considerando essas informações, é possível que os filhos dos funcionários do Parque Florestal José Segadas Viana também tenham auxiliado na distribuição das sementes nas covas, em 1947 e nos anos seguintes, quando ocorreram plantios.

No Parque Florestal José Segadas Viana, em 1947, o plantio foi realizado diretamente no talhão e em cada cova foram depositadas duas ou três sementes. ${ }^{21}$ De acordo com os dados reunidos na Tabela 1, 0 espaçamento utilizado entre as linhas foi de $1,20 \times 0,80$ metros nos talhões 4 e 39 , plantados em agosto e nos talhões 42 e 49, plantados em outubro. 0 espaçamento de 1,50 x 1,50 metros foi utilizado nos talhões 40, 46 e 47, plantados em agosto e no 48, plantado em setembro. Logo, é possível notar que não existia um espaçamento padrão definido e que experiências eram feitas.

A quinta etapa descrita nos Registros de Talhões era o "replantio". Ocorria depois de um determinado tempo, quando se verificava que algumas das sementes não germinaram ou quando, por condições bióticas ou abióticas desfavoráveis, as araucárias se desenvolveram. A sexta etapa consistia na contagem de plantas existentes ou que haviam padecido e era realizada anualmente. Simultaneamente à quinta e à sexta etapas ocorriam os "tratos culturais", que consistiam na limpeza do talhão, realizada, na maioria das vezes, manualmente com roçada e capina. Os tratos culturais deveriam acontecer com certa frequência e por diversos anos, de forma a melhorar, na compreensão dos técnicos, as condições de sobrevivência do monocultivo florestal.

\footnotetext{
${ }^{17}$ Instituto Nacional do Pinho, "Relatório dos serviços realizados no Parque Florestal dos Pardos durante 0 ano de 1946", in Parque Florestal dos Pardos 1, (1946): 16-17.

${ }^{18}$ Ibidem, 16.

${ }^{19}$ Entrevista com Ermes Miorando, por Débora Nunes de Sá. 11 fev. 2016. (gravação).

${ }^{20}$ Entrevista com Alfredo da Rosa, por Débora Nunes de Sá. 11 fev. 2016. (gravação).

${ }^{21}$ Universidade Federal de Santa Maria, Plano de Manejo da Floresta Nacional de Passo Fundo. (Santa Maria: Universidade Federal de Santa Maria, 1989).
} 
0 Chefe da Divisão de Florestamento e Reflorestamento em nível federal, Eudoro Barros, afirmou que um dos elementos que por tempos prejudicou a sobrevivência das araucárias não só no Parque Florestal José Segadas Viana, mas também nos outros parques do Instituto Nacional do Pinho, demandando vários replantios, foram os tratos culturais a enxada e a aração das terras por animais, que de acordo com ele "não podiam, como é lógico, manter limpas as plantações no ritmo requerido. Daí porque, a contagem levada a efeito em 1952, acusou uma sobrevivência de oito milhões de pinheiros, dos vinte e dois milhões plantados entre 1944 e 1950."22 Contudo, essa afirmação é estranha, pois no ambiente florestal a araucária cresce em interação com outras espécies e a presença de outras plantas não impede o seu desenvolvimento. Pesquisa recente dos botânicos Thiago Valente, Raquel Negrelle e Carlos Sanquetta confirmou que a araucária se regenera no interior de florestas maduras, mesmo que haja pouca luminosidade. ${ }^{23}$

Em 1948 o Instituto Nacional do Pinho selecionou 15 áreas de amostras para estudos dos plantios realizados em 1947 no Parque Florestal José Segadas Viana, o que originou os dados apresentados na Tabela 2, que indicam a percentagem de falhas, a altura das plantas e 0 seu estado.

Tabela 2 - Percentagem de falhas em 15 amostras de áreas plantadas em 1947 no Parque Florestal José Segadas Viana

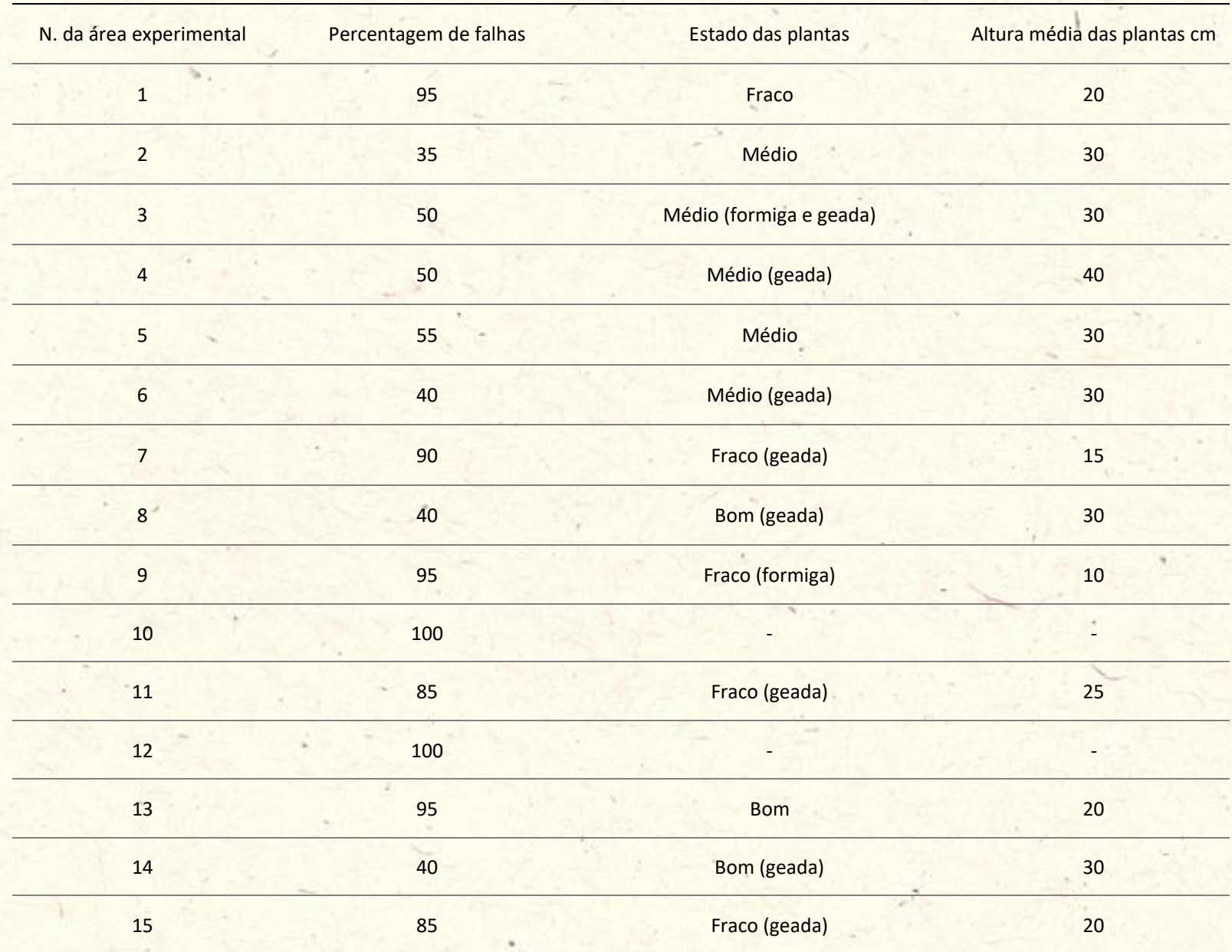

Fonte: Eudoro Haeckel Lins de Barros, "0 Relatório Rogers e o trabalho do Instituto Nacional do Pinho" in Anuário Brasileiro de Economia Florestal 6, (1953): 360-370.

${ }^{22}$ Eudoro Haeckel Lins de Barros, "As atividades do Instituto Nacional do Pinho", in Anais da Reunião Florestal de Itatiaia 12, (1957): 83.

${ }^{23}$ Thiago Piazzetta Valente, Raquel Negrelle; Carlos Roberto Sanquetta "Regeneração de Araucaria angustifolia em três fitofisionomias de um fragmento de Floresta Ombrófila Mista", "in Iheringia 1, (2010): 17-24, https://isb.emnuvens.com.br/iheringia/article/view/77. 
Eudoro H. Lins de Barros, agrônomo da Divisão de Florestamento e Reflorestamento do Instituto Nacional do Pinho, apontou que as terras onde foram realizados os plantios em 1948, eram antigas terras de culturas infestadas por "ervas daninhas" e que, além disso, geadas e ataques de formigas resultaram no baixo índice de sobrevivência, que alcançou $70 \%$ de falhas nos plantios tomados como amostra. ${ }^{24}$ Para combater as formigas e outros insetos que prejudicavam as plantações, durante os anos de $1947 \mathrm{e}$ 1948, o Parque adquiriu diversos produtos químicos: $5 \mathrm{~kg}$ de arsênico, $2 \mathrm{~kg}$ de enxofre, 13 garrafões e dois engradados de formicida, 6 latas de inseticida, 40 latas de cianogás e três bombas de cianogás. ${ }^{25}$ No início do século XX, as formigas foram vistas como causadoras de diversos prejuízos aos agricultores no Rio Grande do Sul. Na agricultura colonial do início do século XX, uma das soluções para o problema da presença de insetos foi 0 uso de venenos que continham 0 arsênico ${ }^{26}$ Esse elemento químico teve diversos usos ao longo do tempo: foi utilizado, durante 0 século XIX e até meados do século XX, como agente terapêutico no tratamento de dermatoses e alguns compostos eram empregados como tônicos no combate a diversas doenças; durante a Segunda Guerra Mundial foi utilizado como gás letal. Diversos casos confirmaram que seu uso causa câncer e é altamente tóxico $0{ }^{27}$ Durante o período em que 0 Parque utilizou o produto, ele era vendido livremente nos estabelecimentos agropecuários como pesticida. Hoje seu uso é restrito a laboratórios.

A partir de 1947, procedeu-se os replantios dos talhões e, exceto pelo talhão 42, em 1948 todos os talhões receberam os replantios. 0 espaçamento dos replantios não foram registrados e o número de covas variou em relação a do primeiro plantio. Também não foi registrada a área do efetivo replantio, impossibilitando uma comparação de dados com o plantio. Além dos replantios realizados anualmente, o Parque continuou a realizar novos plantios entre 1948 e 1951, conforme os dados apresentados na Tabela 3.

Tabela 3 - Plantio de Araucaria angustifolia no Parque Florestal José Segadas Viana de 1948 a 1951

\begin{tabular}{ccccccc}
\hline $\begin{array}{c}\text { Ano de } \\
\text { plantio }\end{array}$ & Talhão & $\begin{array}{c}\text { Área em hectares } \\
\text { (ha) }\end{array}$ & Mês do Plantio & Espaçamento em metros & N. de covas & Sementes em kg \\
\hline 1948 & 13 & 4,7 & Junho & $1,20 \times 0,80$ & 11.250 & 900 \\
\hline 1948 & 14 & 6,9 & Junho & 13.500 & 1.080 \\
\hline 1948 & 45 & 4,8 & Junho & $1,20 \times 0,80$ & 16.500 & 1.320 \\
\hline 1948 & 50 & 2,8 & Junho & $1,20 \times 0,80$ & 5.500 & 440 \\
\hline 1948 & 51 & 8,8 & Junho & $1,20 \times 0,80$ & 22.750 & 1.820 \\
\hline 1948 & 52 & 2 & Junho & $2,00 \times 2,00$ & 5.500 & 440 \\
\hline 1948 & 53 & 4,4 & Junho & $1,20 \times 0,80$ & 11.250 & 900 \\
\hline 1948 & 54 & 6,8 & Junho & $1,20 \times 0,40$ & 13.500 & 1.080 \\
\hline 1949 & 3 & 2,3 & Maio & $1,20 \times 0,80$ & 25.082 & 650 \\
\hline 1949 & 29 & 10,8 & Juḷo & $1,20 \times 0,80$ & 125.033 & 3.157 \\
\hline
\end{tabular}

\footnotetext{
${ }^{24}$ Eudoro Haeckel Lins de Barros, "O Relatório Rogers e o trabalho do Instituto Nacional do Pinho" in Anuário Brasileiro de Economia Florestal 6, (1953): 360-370.

${ }^{25}$ Instituto Nacional do Pinho. Livro Caixa n. 1, de 1947-1949 in Parque Florestal do Instituto Nacional do Pinho. Arquivo da Floresta Nacional de Passo Fundo.

${ }^{26}$ Marcos Gerhardt, História ambiental da Colônia ljuhy. (ljuí: Editora Unijuí, 2009).

${ }^{27}$ Bernardo Gontijo, Flávia Vasques Bittencourt "Arsênico - Uma revisão histórica", in Anais Brasileiros de Dermatologia 1, (2005): 81-85, http://www.anaisdedermatologia.org.br/detalhe-artigo/16/Arsenio---Uma-revisao-historica.
} 


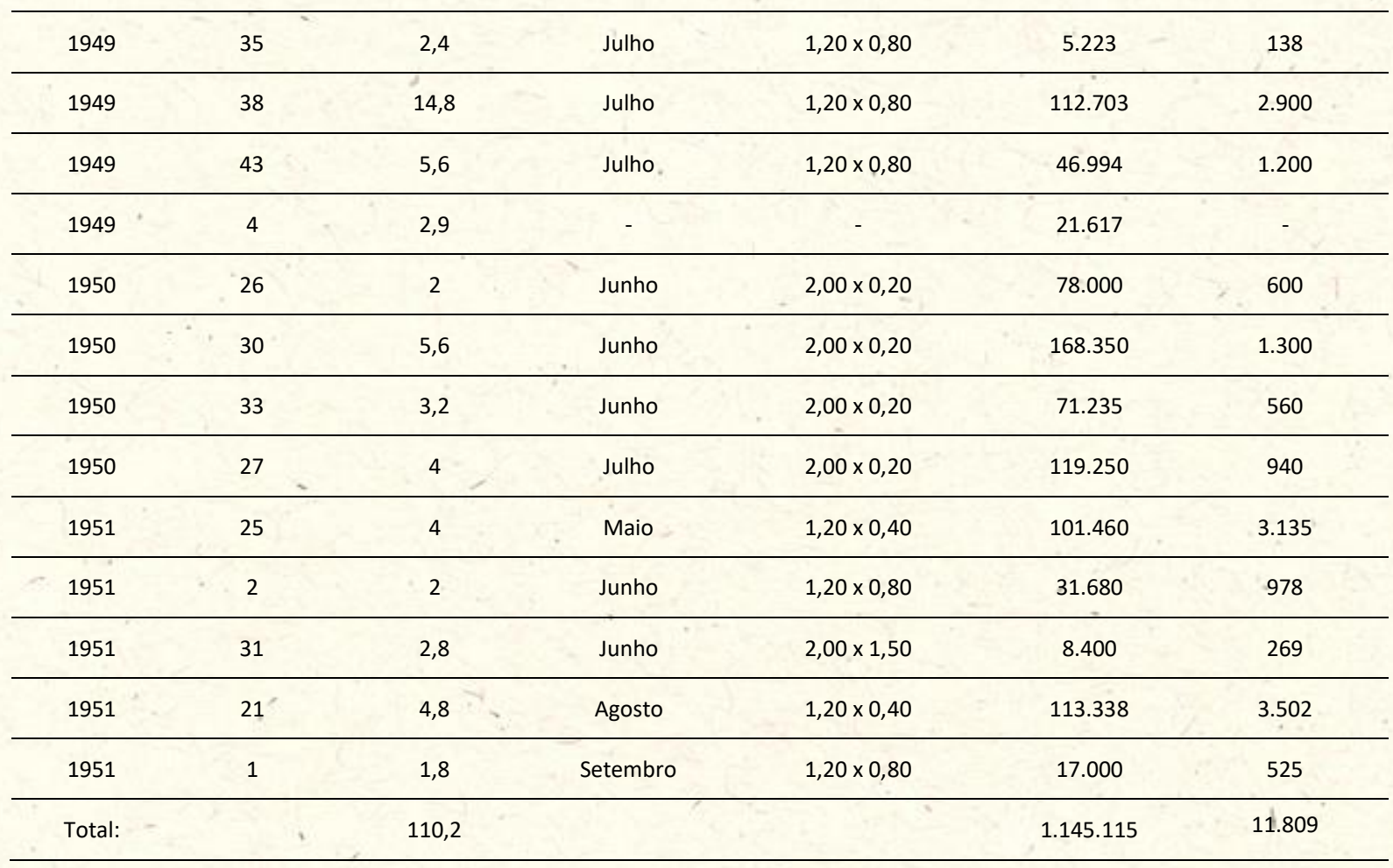

Fonte: Elaborada pelos autores a partir de Instituto Nacional do Pinho. Parque Florestal José Segadas Viana, Mato Castelhano - Passo Fundo. Registros de Talhões n. 13, 14, 45, 50, 51, 52, 53, 54, 3, 29, 35, 38, 43, 4, 26, 20, 33, 27, 25, 2, 31, $21,1$. 1947-1951. Arquivo da Floresta Nacional de Passo Fundo.

Nota: 0 Talhão 4 recebeu, em 1979, o plantio de Eucalyptus spp. 0 Talhão 27, em 1982, foi renomeado para 61.

Observa-se que o espaçamento utilizado nos plantios de 1947 (Tabela 1) e 1948, que foram de $1,20 \times 0,40$ metros, 1,20 x 0,80 metros, 1,50 x 1,50 metros e 2,00 × 2,00 metros. As primeiras medidas, menores que 1,50 metros, permitiam uma grande densidade de árvores no talhão. Isso acabou por prejudicar os tratos culturais manuais e a limpeza realizada não manteve as plantações livres das plantas indesejadas, 0 que pode ter interferido na sobrevivência das mudas de araucária. Outras fontes consultadas informam que os nove talhões plantados em 1947 e os oito plantados em 1948, não sobreviveram. Além dos fatores apontados anteriormente, como a presença de formigas, as geadas, 0 espaçamento reduzido e a deficiência nos tratos culturais, a pouca profundidade do solo no coveamento foi um dos motivos. ${ }^{28}$

Em 1949 foram plantados seis talhões, dos quais, exceto pelo Talhão 4, todos receberam 0 espaçamento de $1,20 \times 0,80$ metros. 0 Talhão 3 foi plantado em maio e 0 restante em julho, com ressalva para o Talhão 4, cujo registro é incompleto. Esse talhão havia sido plantado em 1947 e em 1948 recebeu um novo plantio, o que decorreu da baixa sobrevivência das mudas, sendo o plantio de 1949 considerado como o primeiro no talhão. ${ }^{29}$

Além do plantio de araucária, era realizado no Parque Segadas Viana o plantio de cereais e de outros vegetais: arroz, feijão, aveia, trigo, milho e batata. Durante 1948 foram adquiridos $600 \mathrm{~kg}$ de trigo em grão para semente e foram vendidos $1: 225 \mathrm{~kg}$ de feijão, ao valor de $\operatorname{Cr} \$ 1,50 / \mathrm{kg}$, e mais $10.380 \mathrm{~kg}$ de milho, ao valor de Cr\$ 0,50/kg, aos operários e funcionários do Parque. 0 engenheiro australiano Rogers, entretanto, avaliou que o uso do solo dos parques florestais do Instituto Nacional do Pinho para a

\footnotetext{
${ }^{28}$ Universidade Federal de Santa Maria, Plano de Manejo da Floresta Nacional de Passo Fundo. (Santa Maria: Universidade Federal de Santa Maria, 1989). Instituto Nacional do Pinho. Parque Florestal "José Segadas Viana", Mato Castelhano - Passo Fundo. Registro de Talhão n. 4, 1947. Arquivo da Floresta Nacional de Passo Fundo.

${ }^{29}$ Instituto Nacional do Pinho. Parque Florestal José Segadas Viana, Mato Castelhano - Passo Fundo. Registros de Talhões $\mathrm{n}$. 3, 29, 35, 38, 43, 4. 1947; 1949. Arquivo da Floresta Nacional de Passo Fundo.
} 
plantação de alimentos necessitava de um estudo completo, pois a competição de raízes que se estabeleceu entre as plantas, principalmente a do milho com a da araucária, é considerável, causando efeitos adversos na sobrevivência e no crescimento das árvores. ${ }^{30}$ Ermes Miorando, que trabalhou na FLONA PF de 1967 a 1996, contou que, durante o período em que Paulo Flores administrou a unidade (1952 a 1980), ele:

\begin{abstract}
Deixava a gente plantar em parte do pinhal, tinha um limite para deixar, uma rua, tinha que deixar 20 metros em caso de um incêndio, pra caminhar, passar o pessoal, pra não dificultar para passar para 0 outro lado. Aquilo ali era tudo limpo, conservado, o pessoal conservava bem aquilo ali, sempre tinha um trator pra passar grade, pra não deixar criar mato, pra poder virar uma sede. Então o chefe deixava a gente plantar alguma coisinha, só não podia vender, podia plantar para tratar o boi, as galinhas, mas não podia comercializar, mas para consumo próprio não tinha problema. Colhia as próprias plantas. Produtos sem veneno. ${ }^{31}$
\end{abstract}

Esse testemunho informa que o cultivo agrícola dos tempos iniciais, prosseguiu no período seguinte. A coexistência de variadas atividades agrícolas como a monocultura de araucária e a produção de alimentos para consumo, evidencia os diferentes usos da terra que foram permitidos pelos gestores ou se tornaram práticas temporárias no interior da unidade.

\title{
A mecanização do Parque Florestal
}

Eudoro Barros afirmou que condições naturais, formigas e lagartas foram responsáveis por perdas consideráveis em todos os parques florestais do INP e que, durante 1951 e 1952, os parques do Instituto Nacional do Pinho dedicaram-se às reformas, aos replantios e a adquirir experiência com tratores. ${ }^{32}$ Para esse administrador, a sobrevivência das araucárias estava condicionada ao preparo das terras e aos tratos culturais, que deveriam ser realizados mecanicamente. A partir de 1952, os parques passaram a utilizar espaçamento que facilitava a limpeza com máquinas. Segundo Barros: "Embora não possua o INP as maquinas mais adequadas, pois estamos empregando algumas apenas adaptadas, podemos assegurar que o sucesso dos tratos culturais está na mecanização, que torna esse trabalho mais rápido e econômico." ${ }^{33}$ Com 0 trabalho mecanizado e 0 conhecimento produzido nas atividades experimentais, 0 Instituto passou a viver uma nova fase, pois aplicou outras técnicas na preparação dos terrenos e nos tratos culturais. ${ }^{34}$

Decorridos dois anos em que o Parque Florestal José Segadas Viana se dedicou exclusivamente aos replantios, em agosto de 1954 realizou o plantio do Talhão 20 com espaçamento de 2,00 x 1,00 metros. Diferentemente dos outros plantios realizados até 1951, nos quais as sementes provinham de Passo Fundo e municípios próximos, em 1954 a procedência dos $756 \mathrm{~kg}$ de pinhão, utilizados em 61.580 covas abertas em 12 hectares, era do município de Canela. ${ }^{35}$. A Figura 1 representa dois Talhões plantados em 1954.

Borris Kossoy afirmou que a fotografia "ou um conjunto de fotografias apenas congelam, nos limites do plano da imagem, fragmentos desconectados de um instante de vida das pessoas, coisas, natureza, paisagens urbanas e rurais." ${ }^{36}$ Um registro fotográfico precisa ser interpretado, extraindo-se dele particularidades do momento histórico dentro do contexto estudado.

\footnotetext{
${ }^{30}$ Roger, L. R, "Problemas silviculturais da Araucaria angustifolia: relatório ao governo do Brasil", in Anuário Brasileiro de Economia Florestal 6, (1953): 321.

${ }^{31}$ Entrevista com Ermes Miorando, por Débora Nunes de Sá, 11 fev. 2016. (gravação).

${ }^{32}$ Eudoro Haeckel Lins de Barros, "As atividades do Instituto Nacional do Pinho", in Anais da Reunião Florestal de Itatiaia 12, (1957): 77-83.

33 Ibidem, p. 83.

34 Ibidem, p. 83.

${ }^{35}$ Instituto Nacional do Pinho. Parque Florestal José Segadas Viana, Mato Castelhano - Passo Fundo. Registro do Talhão $\mathrm{n}$. 20. 1954. Arquivo da Floresta Nacional de Passo Fundo.

${ }^{36}$ Boris Kossoy, Fotografia \& História. (São Paulo: Ateliê Editorial, 2001), 114-115.
} 
Figura 1 - Talhões "1-S" e "2-S" em 1954

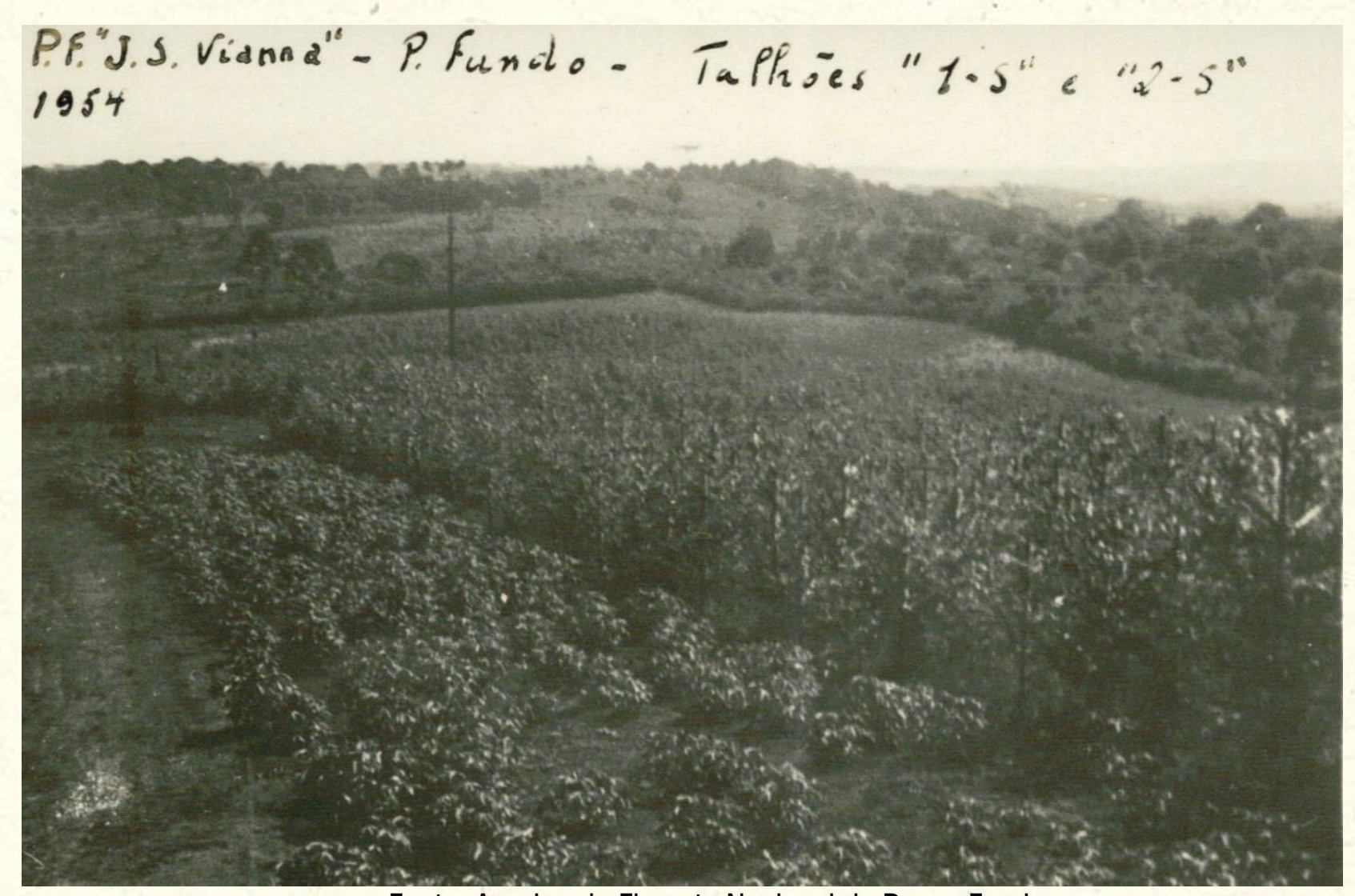

Fonte: Arquivo da Floresta Nacional de Passo Fundo.

A Figura 1 retrata araucárias em crescimento que foram plantadas nos talhões "1-S" e "2-S", possivelmente os talhões 1 e 2 plantados em 1951. Observa-se na Figura 1, 0 adensamento das araucárias, resultado do espaçamento utilizado, de $1,20 \times 0,80$ metros. ${ }^{37}$ Além disso, percebe-se a existência de outra cultura (possivelmente mandioca) para aproveitar 0 terreno. Em outros parques, 0 Instituto também cultivou milho entre as plantações de araucária, com a finalidade de testar variadas técnicas culturais. Neles, além de estudos sobre o plantio de araucária, foram realizados experimentos com outras espécies florestais de valor econômico: cangerana (Cabralea canjerana), cedro (Cedrus spp) e imbuia (Ocotea porosa). ${ }^{38}$

0 Talhão 25 nos permite identificar uma trajetória: com quatro hectares de área, foi plantado em maio de 1951 com 3.135 quilogramas de pinhão, distribuídos em 101.460 covas. 0 espaçamento utilizado foi de 1,20 x 0,40 metro. Em 1954 a contagem realizada pelo Parque para fins de controle estatístico identificou 47.365 araucárias no talhão e em 1962, 27.756 araucárias. Em 1971 um desbaste realizado reduziu e a área deste talhão para 1,6 hectares ${ }^{39}$ A Figura 20 representa em 1959 e mostra a densidade de plantas que atingiram tamanho significativo em oito anos.

\footnotetext{
${ }^{37}$ Instituto Nacional do Pinho. Parque Florestal José Segadas Viana, Mato Castelhano - Passo Fundo. Registros de Talhões $\mathrm{n}$. 1 e 2. 1951. Arquivo da Floresta Nacional de Passo Fundo.

${ }^{38}$ Eudoro Haeckel Lins de Barros, "O Relatório Rogers e o trabalho do Instituto Nacional do Pinho" in Anuário Brasileiro de Economia Florestal 6, (1953), 343.

${ }^{39}$ Instituto Nacional do Pinho. Parque Florestal "José Segadas Viana", Mato Castelhano - Passo Fundo. Registro de Talhão n. 25. 1951. Instituto Nacional do Pinho. Ficha de Dados Estatísticos Talhão n. 25. 1954. Arquivo da Floresta Nacional de Passo Fundo.
} 
Figura 2 - 0 talhão 25 em 1959

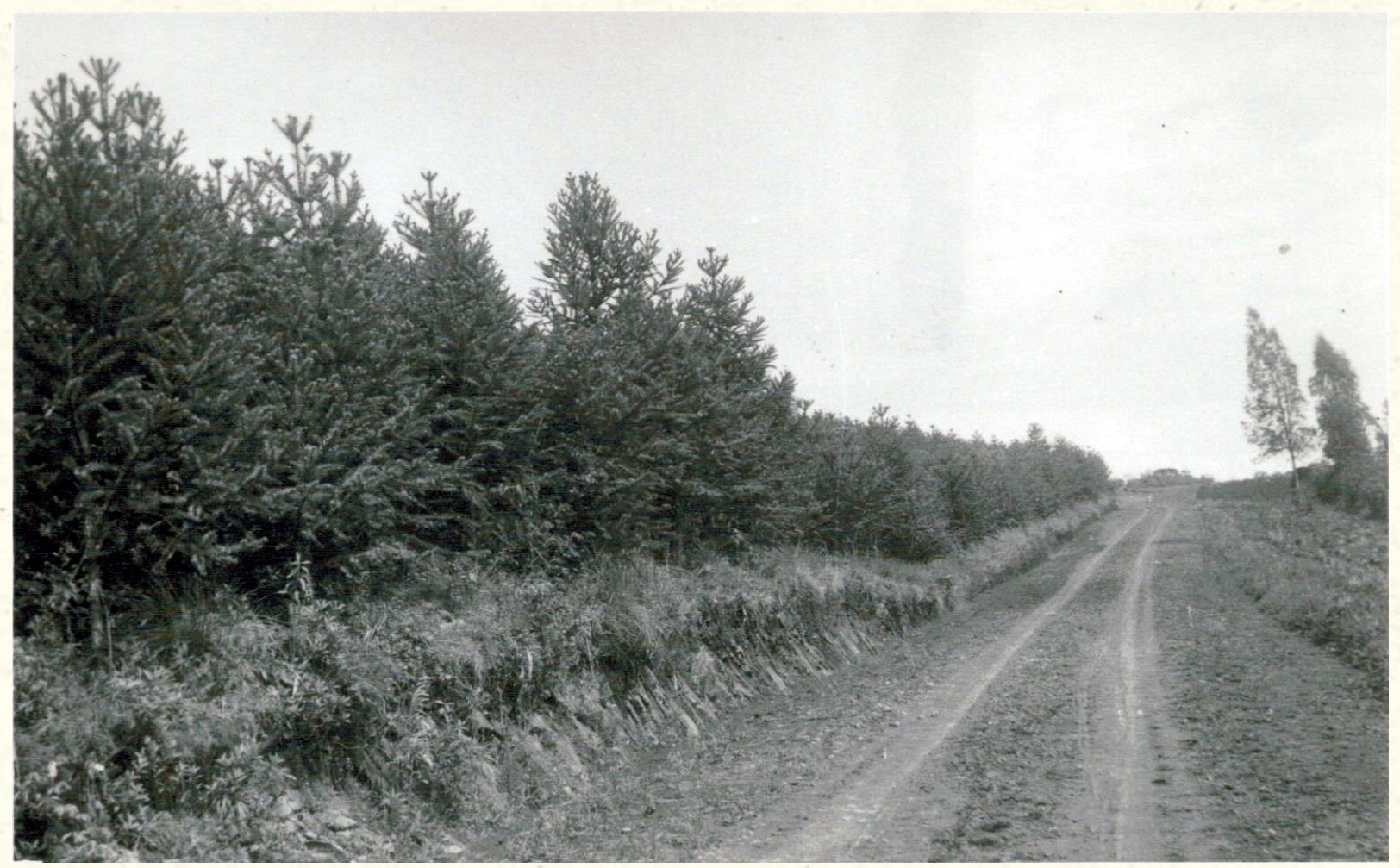

Fonte: Arquivo da Floresta Nacional de Passo Fundo.

Tabela 4 - Plantio de Araucaria angustifolia no Parque Florestal José Segadas Viana em 1955 e 1957

\begin{tabular}{ccccccc}
\hline Data de plantio & Talhão & Área (ha) & $\begin{array}{c}\text { Espaçamento em } \\
\text { metros }\end{array}$ & Procedência sementes & $N^{\circ}$ de covas & $\begin{array}{c}\text { Sementes em } \\
\mathrm{kg}\end{array}$ \\
\hline 1955 & 6 & 5,2 & $1,20 \times 0,80$ & Passo Fundo & 59.385 & 1.028 \\
\hline 1955 & 14 & 12 & $2,00 \times 1,00$ & Canela & 57.135 & 956 \\
\hline Jun. 1955 & 16 & 3,6 & $2,00 \times 1,00$ & Canela & 17.365 & 538 \\
\hline Jul. 1955 & 15 & 17,6 & $2,00 \times 1,00$ & Canela & 82.670 & 1.906 \\
\hline Set. 1955 & 12 & 16,8 & $2,00 \times 1,00$ & Canela & 100.880 & 2.230 \\
\hline Set. 1955 & 19 & 26 & $2,00 \times 1,00$ & Canela & 128.130 & 2.718 \\
\hline 1957 & 7 & 12,4 & $1,50 \times 1,50$ & São Francisco de Paula & 79.108 & 1.488 \\
\hline 1957 & 44 & 30 & $1,00 \times 1,00$ & São Francisco de Paula & 404.987 & 7.619 \\
\hline 1957 & 11 & 14,8 & & Canela & 143.009 & 2.690 \\
\hline
\end{tabular}

Fonte: Elaborada pelos autores a partir de Instituto Nacional do Pinho. Parque Florestal José Segadas Viana, Mato Castelhano - Passo Fundo. Registro de Talhões n. 6, 14, 16, 15, 12, 19, 7, 44, 11. 1955; 1957. Arquivo da Floresta Nacional do Passo Fundo.

Notas: 0 plantio do Talhão 14, em 1948, não sobreviveu. Em 1955, novo Registro foi feito para os plantios daquele ano. 
Não se encontrou no Arquivo da FLONA PF o Registro do Talhão 10. Todavia, encontrou-se do Talhão "X", plantado em 1956, que possivelmente é o mesmo. Os dados registrados são imprecisos, por isso optou-se por não inclui-los na Tabela 4.

No decurso de 1956, entre as diversas atividades desenvolvidas no Parque, foram realizadas capinas e roçadas de limpeza dos talhões. Em 1955 e 1957, sementes de araucária foram trazidas dos municípios onde existiam os outros dois parques florestais do Instituto Nacional do Pinho no Rio Grande do Sul: Canela e São Francisco de Paula. Essa informação revela que houve uma interação e troca de conhecimentos e recursos entre eles. Apesar disso, é possível identificar a deficiência dessa interação nas palavras de Paulo Flores, servidor do Parque que se aposentou em 1980 e escreveu uma carta de despedida direcionada a seus superiores e colegas:

Desde nossa admissão nesta Floresta no ano de 1952, aplicamos nossos conhecimentos baseados na experiência e sentimos que faltou um entrosamento entre as direções das três Florestas neste Estado e mesmo dos demais Estados, pois um melhor conhecimento dos serviços aplicados em outros órgãos florestais, em muito facilitaria nosso trabalho. Nos 28 anos que aqui permanecemos não nos foi dado o privilégio de conhecermos os demais órgãos deste Estado. Os que conhecemos foi por iniciativa própria, por ocasião de nossas férias regulamentares, em rápidas passagens. ${ }^{40}$

Assim, mesmo com as diversas trocas de sementes e informações entre os parques florestais, Paulo Flores lamentou que, durante 28 anos, o INP e, depois, o IBDF não incentivaram ou possibilitaram que os funcionários conhecessem as outras unidades. A maior parte dos contatos entre elas era realizado pelo silvicultor regional que acompanhava os trabalhos nos três parques florestais do RS e pelos motoristas que realizavam 0 transporte de sementes ou mudas e de maquinários. ${ }^{41}$

No intervalo de 1958 a 1959, não foram realizados plantios novos no Parque Florestal José Segadas Viana. Isso decorreu, de acordo com 0 então presidente do INP, Aristides Largura, da constatação de que, essa unidade, assim como o Parque Florestal Joaquim Francisco Assis Brasil, em São Francisco de Paula, possuía subsolo pedregoso, que prejudicava os monocultivos. Além disso, os plantios que haviam sido realizados anteriormente demandavam tratos culturais que "acarretam de ano para ano uma despesa maior, embora feitos por empreitada." 42

Três talhões com araucária foram plantados em 1960: 09 em julho e os talhões 32 e 34 em agosto. 0 espaçamento utilizado foi de 2,00 x 0,50 metros, totalizando 445.565 covas e $9.376 \mathrm{~kg}$ de sementes, que procediam do município de Canela RS. Na contagem realizada em 1961, registrou-se que no Talhão 9 a sobrevivência foi de $49 \%$, enquanto que nos talhões 32 e 34 a sobrevivência chegou a $61 \%$ e $49 \%$, respectivamente. Não há registros de que tenham ocorrido replantios nos referidos talhões e não foram apontadas as causas que levaram a mortalidade de parte das araucárias. ${ }^{43}$

Durante a década de 1960, parte considerável da superfície do Parque Florestal José Segadas Viana encontrava-se coberta com monocultivos de araucária. Nesse período, cinco novos talhões foram plantados, conforme os dados reunidos na Tabela 5.

\footnotetext{
${ }^{40}$ Paulo Flores. Carta remetida aos supervisores e colegas em 1980. Arquivo da Floresta Nacional de Passo Fundo.

${ }^{41}$ Id. Entrevista com Arlindo Frainer, por Débora Nunes de Sá. 11 fev. 2016. (gravação). Instituto Nacional do Pinho, "Os serviços de reflorestamento do I.N.P. in Anuário Brasileiro de Economia Florestal 2, (1949), 403-411.

${ }^{42}$ Aristides Largura, "A vida econômica e financeira do I.N.P." in Anuário Brasileiro de Economia Florestal 11, (1959), 13.

${ }^{43}$ Instituto Nacional do Pinho. Parque Florestal José Segadas Viana, Mato Castelhano - Passo Fundo. Registros de Talhões $\mathrm{n}$.

9; 32; 34. 1960. Arquivo da Floresta Nacional de Passo Fundo.
} 
Tabela 5 - Plantio de Araucaria angustifolia no Parque Florestal José Segadas Viana após 1960

\begin{tabular}{ccccccc}
\hline $\begin{array}{c}\text { Ano de } \\
\text { plantio }\end{array}$ & Talhão & $\begin{array}{c}\text { Área } \\
\text { (ha) }\end{array}$ & $\begin{array}{c}\text { Espaçamento em } \\
\text { metros }\end{array}$ & Procedência sementes & N. de covas & Sementes em kg \\
\hline 1962 & 17 & 10 & $2,00 \times 0,50$ & São Francisco de Paula & 95.345 & 1.664 \\
\hline 1962 & 18 & 14 & $2,00 \times 0,50$ & São Francisco de Paula & 139.567 & 2.435 \\
\hline 1962 & 23 & 40 & $2,00 \times 0,50$ & São Francisco de Paula & 394.899 & 6.891 \\
\hline 1965 & $28 \mathrm{~A}$ & 5 & $2,00 \times 1,00$ & Parque Florestal José Segadas & 24.528 & 465 \\
\hline 1968 & 22 & 6 & $2,00 \times 0,50$ & Siana & 57.837 & 1.010 \\
\hline
\end{tabular}

Fonte: Elaborada pelos autores a partir de Instituto Nacional do Pinho. Parque Florestal José Segadas Viana, Mato Castelhano - Passo Fundo. Registro de Talhões n. 17, 18, 23, 28 A, 22. 1962; 1965; 1968. Arquivo da Floresta Nacional do Passo Fundo.

0 objetivo era produzir matéria-prima para a indústria madeireira e de celulose. Dessa forma, os monocultivos foram manejados a fim de atender a essa demanda. 0 manejo era realizado pelo desbaste baixo, seletivo e moderado, no qual priorizava-se a remoção das araucárias "dominadas", porque essa técnica auxiliava na diminuição do adensamento das árvores, tendo em vista que a maior parte dos espaçamentos utilizados nos plantios eram reduzidos e prejudicavam 0 seu crescimento, 0 que foi percebido à medida que se desenvolviam. Logo, a retirada das araucárias "dominadas", isto é, aquelas que cresceram menos, permitia o desenvolvimento daquelas com maiores dimensões.

A venda das araucárias para madeireiras, serrarias ou outros interessados era realizada via concorrência pública, sendo que a empresa vencedora ficava responsável por realizar o corte e a retirada da madeira do talhão. Os Planos de Manejo de 1982 e 1989 relataram que este tipo de manejo, que era realizado em etapas, danificava as outras araucárias do talhão. ${ }^{44}$ Atualmente, ainda é a empresa vencedora da concorrência pública que realiza a retirada das árvores no talhão. As plantas que devem ser derrubadas são selecionadas pelos técnicos ambientais da FLONA PF.

No ano de 1982, foi registrada a existência de 18 serrarias no município de Passo Fundo, ${ }^{45}$ que poderiam consumir produtos florestais da FLONA PF. Num raio de 120 quilômetros, o número aumentava para 250, sendo consideradas nessa classificação as serrarias para 0 desdobro de toras, fabricação de mobília, de carrocerias e de caixotarias. ${ }^{46}$ Guias de Desbaste arquivadas na FLONA PF identificam algumas das empresas que adquiriram toras de araucária em 1982, como a Madeireira Ibirajara, localizada em Bento Gonçalves e a Industrial Madeireira Kurtz, de Passo Fundo.

Diversos são os fatores que influenciam na produção de um talhão, parte deles depende da ação humana: a preparação das terras, o espaçamento entre uma árvore e outra e os tratos culturais. Outros são aqueles de ordem abiótica: humidade, composição química do solo, luz e temperatura ou biótica: especialmente a interação com animais silvestres e com outras plantas. A combinação de diversos elementos naturais e culturais constitui o agroecossistema e influencia no rendimento econômico. Donald Worster avaliou que cada agroecossistema possui particularidades, contudo, independente delas, todos eles "estão sujeitos às leis da ecologia, e estas mesmas leis governam as florestas selvagens, as matas, as savanas e os pastos, determinando quão estáveis ou flexíveis ou sustentáveis eles são como

\footnotetext{
${ }^{44}$ Universidade Federal de Santa Maria, Plano de Ordenamento da Floresta Nacional de Passo Fundo - RS. (Santa Maria: Universidade Federal de Santa Maria, 1982).

${ }^{45}$ Considera a configuração territorial de 1982, que abrigava o distrito de Mato Castelhano, emancipado em 1992.

${ }^{46}$ Universidade Federal de Santa Maria, Plano de Ordenamento da Floresta Nacional de Passo Fundo - RS. (Santa Maria: Universidade Federal de Santa Maria, 1982).
} 
entidades coletivas".47 Logo, embora "tenha algo de um artefato humano, o sistema agroecológico permanece inevitavelmente dependente do mundo natural [...]. É um rearranjo, não uma anulação dos processos naturais".48 Desse modo, os talhões cultivados com araucária no Parque Segadas Viana produziram quantidades diferentes de material lenhoso em função de inúmeros fatores bióticos, abióticos e culturais.

\section{Considerações finais}

Interpretando as diversas fontes de pesquisa disponíveis, referentes ao monocultivo de araucária no Parque Florestal José Segadas Viana e na FLONA PF, que possibilitaram compreender como se deu a constituição de um agroecossistema específico, constatou-se que 0 conhecimento produzido sobre a ecologia e 0 cultivo da espécie se originou principalmente da observação empírica. A técnica empregada foi o plantio direto, no qual se utilizavam duas ou três sementes de araucária por cova. Os replantios eram realizados quando ocorria baixa sobrevivência, a exemplo de alguns talhões que tiveram a araucária replantada ou substituída por povoamentos de Pinus spp durante as décadas de 1960 e 1970. Os espaçamentos iniciais eram reduzidos e, consequentemente, os talhões apresentavam grande densidade de plantas. 0 sistema adotado no desbaste, foi aquele que privilegiava a produção de madeira de maior diâmetro para utilização em serrarias. Foi a partir de 1955 (exceto em 1957), que o espaçamento utilizado passou, como padrão, a ser maior (2,00 x 0,50; 2,00 x 1,00 m). Isso ocorreu, possivelmente, porque os plantios da década de 1940 e início de 1950, em crescimento, demostraram que um espaçamento reduzido era prejudicial ao desenvolvimento da espécie e dificultava a limpeza dos talhões e os desbastes.

Worster argumentou que o sistema agroecológico de monocultura é aquele em que parte da natureza "vem sendo reconstituída a ponto de produzir uma única espécie, que está sendo plantada na terra apenas porque em algum lugar há uma forte demanda de mercado por ela".49 Isso se aplica aos monocultivos de araucária estudados, uma vez que seguiram a lógica do capitalismo, isto é, visavam compensar a decrescente disponibilidade de matéria-prima florestal no mercado regional, resultado do intenso desmatamento ocorrido na Floresta Ombrófila Mista no final do século XIX e início do XX. Isso impulsionou o Instituto Nacional do Pinho a aplicar o "Plano de Reflorestamento", por meio dos parques florestais na região de ocorrência endêmica da araucária. Não houve, portanto, o intuito de promover a conservação ou restauração do ambiente florestal, mas de produzir matéria-prima para atender as demandas da indústria madeireira e de celulose, bem como incentivar a prática da monocultura florestal por particulares.

0 historiador canadense Stuart McCook analisou que as ciências naturais foram introduzidas na América durante a conquista europeia, contudo, na América Latina, foi durante 0 século XIX que a elite (econômica, intelectual e política) passou "a recorrer sistematicamente às ciências naturais para inventariar o mundo natural e para (idealmente) usar a natureza como promotora do desenvolvimento nacional". Assim, na maior parte dos séculos XIX e XX "o principal objetivo das ciências era manter as paisagens 'pródigas' da América Latina tão produtivas quanto possível”.50 No caso da Floresta Ombrófila Mista, aqui tomada como a região fitogeográfica onde se inseriu o Parque Florestal José Segadas Viana e a FLONA PF, a maior parte da paisagem "pródiga" havia sido alterada pelà indústria madeireira e pela colonização por descendentes de imigrantes europeus no início do século XX. Os monocultivos de araucária e, depois, de espécies exóticas, realizados nos parques florestais criados pelo Instituto

\footnotetext{
${ }^{47}$ Donald Worster, "Transformações da terra: para uma perspectiva agroecológica na história", in Ambiente \& Sociedade 2 , (2003), 29-30.

${ }_{48} \mathrm{Id}, 30$.

${ }^{49}$ Donald Worster, "Transformações da terra: para uma perspectiva agroecológica na história", in Ambiente \& Sociedade 2, (2003), 35. (2003, p. 35)

50 Stuart Mccook, "Prodigalidade e sustentabilidade: as ciências naturais e o meio ambiente", in Rachel Carson Center Perspectives 7, (2013), 91.
} 
Nacional do Pinho foram, portanto, agroecossistemas construídos, com a finalidade de gerar conhecimento sobre o manejo florestal e se tornarem economicamente rentáveis. 